\title{
INTERCEPTAÇÕES DE PRODUTOS DE ORIGEM ANIMAL EM FRONTEIRAS TERRESTRES NO BRASIL
}

\section{INTERCEPTION OF ANIMAL-ORIGIN PRODUCTS AT LAND BORDERS IN BRAZIL}

\author{
Mirela Janice Eidt ${ }^{1,2}$ \\ Marcos Eielson Pinheiro de Sá1,2 \\ Concepta Margareth McManus ${ }^{1}$ \\ Cristiano Barros de Melo ${ }^{1 *}$ \\ 1 Universidade de Brasília (UnB/FAV),Programa de Pós-graduação em Ciências Animais, Brasília, DF, \\ Brasil. \\ ${ }^{2}$ Ministério da Agricultura, Pecuária e Abastecimento, Coordenação Geral do Sistema VIGIAGRO, Brasília, \\ DF, Brasil. \\ *Autor para correspondência: cristianomelo@unb.br
}

\begin{abstract}
Resumo
Agentes infecciosos e doenças dos animais podem atravessar fronteiras terrestres e contribuir para a alteração do estado sanitário de países. O objetivo do presente trabalho foi, através de um estudo retrospectivo, identificar os principais produtos de origem animal interceptados e apreendidos em três unidades de vigilância agropecuária (Uvagros/MAPA) localizadas em fronteiras terrestres (secas) na região Norte do Brasil: Assis Brasil e Epitaciolândia, no Acre, e Pacaraima, em Roraima, respectivamente fronteiras com o Peru, Bolívia e Venezuela. Os principais produtos interceptados e apreendidos no trânsito internacional de veículos e passageiros em duas das três unidades foram laticínios, pescados, carnes, embutidos, de uso veterinário e para uso na alimentação animal (ração, medicamentos e insumos) e apícolas. Devem ser melhor avaliadas as possibilidades de introdução de agentes infecciosos e de doenças que podem ameaçar o Brasil, considerando os tipos de produtos apreendidos, considerando o estado sanitário dos países aqui estudados, em face da natureza clandestina do trânsito dos animais e seus produtos por estas fronteiras terrestres.
\end{abstract}

Palavras-chave: doença infecciosa; fiscalização; fronteira; vigilância agropecuária.

\begin{abstract}
Infectious agents and veterinary diseases can be disseminated across borders and contribute to change the country sanitary status. The aim of this study was to identify the main animal products intercepted and seized by the agricultural surveillance units. This paper studied three Agricultural Surveillance Units located at land borders in the North region of Brazil: Assis Brasil and Epitaciolândia (Acre State) and Pacaraima (Roraima State), respectively borders with Peru, Bolivia and Venezuela. The main animal products confiscated were dairy products, fish, meat, sausage,
\end{abstract}


veterinary products (drugs), animal food (pet foods) and apiculture products. Given the clandestine nature of animal transit and its products in these borders, the possibilities of introduction of infectious agents and diseases must be better evaluated, considering the type of products confiscated, as well as the sanitary status of the countries of origin.

Keywords: agricultural surveillance; infectious diseases; inspection; land border.

Recebido em: 29 abril 2013

Aceito em: 18 maio 2015

\section{Introdução}

O Brasil possui uma grande fronteira terrestre que se estende desde a região Sul, passando pela Centro-Oeste até a região Norte. As áreas de fronteira são pouco conhecidas cientificamente e grande parte delas abrange a floresta amazônica (como o Acre e suas fronteiras com Bolívia e o Peru) e uma região de savana (como é o caso de Roraima e a sua fronteira com a Venezuela). Os países fronteiriços da região Norte apresentam "status sanitário" diverso do Brasil e podem apresentar doenças ou agentes infecciosos de interesse veterinário que podem por em risco a agropecuária brasileira.

O monitoramento e a vigilância de doenças são essenciais para os serviços veterinários oficiais de qualquer país e várias formas e ferramentas podem ser usadas para isso, dependendo do objetivo da análise $^{(1,2)}$. Essas questões são muito importantes em regiões de fronteiras internacionais, que são vulneráveis à entrada de animais, seus produtos e subprodutos de forma clandestina e esses podem conter novas cepas/variantes de agentes infecciosos e doenças veterinárias exóticas, que podem causar prejuízos ao país que esteja recebendo esses itens ilegais. No Brasil, o caso clássico da introdução da Peste Suína Africana em 1978 no Estado do Rio de Janeiro causou grande prejuízo econômico e levou seis anos para ser erradicada. O sucesso na erradicação foi em parte devido à velocidade e eficiência do governo brasileiro em executar as ações sanitárias, bem como a utilização de importantes ferramentas epidemiológicas ${ }^{(3,4)}$.

A literatura internacional tem demonstrado a importância de se estudar as fronteiras internacionais, salientando a possibilidade de o trânsito irregular (ilegal) de animais vivos, seus produtos e subprodutos sem certificação sanitária internacional poder apresentar agentes infecciosos perigosos para a saúde pública e a saúde animal dos países receptores desses itens. Como exemplo, doenças como influenza aviária altamente patogênica, doença de Newcastle e micoplasmose aviária (Mycoplasma gallisepticum ou M. synoviae) podem ser disseminadas pelo transporte irregular de aves e produtos avícolas contaminados, bem como suínos e seus produtos clandestinos podem disseminar febre aftosa, peste suína africana, peste suína clássica e doença vesicular suína. Também os ruminantes e seus produtos podem disseminar enfermidades como febre do Vale do Rift, brucelose e listeriose, além da febre aftosa ${ }^{(5-10)}$.

No Brasil, o Sistema de Vigilância Agropecuária Internacional (Vigiagro) é a estrutura organizacional do Ministério da Agricultura, Pecuária e Abastecimento (MAPA) responsável pelos controles oficiais envolvidos nos procedimentos de exportação e importação de animais, vegetais, seus produtos, subprodutos, derivados ou partes, resíduos de valor econômico e insumos agropecuários utilizados nas diversas cadeias produtivas do agronegócio. A fiscalização geralmente 
ocorre baseada na legislação vigente, na experiência e no poder discricionário do servidor público. As unidades localizadas nas fronteiras aqui estudadas aparentemente têm uma movimentação de cargas modesta; entretanto, a sua realidade não era bem conhecida.

Considerando que países como Peru, Bolívia e Venezuela possuem uma condição sanitária distinta do Brasil para inúmeras enfermidades conforme $\mathrm{OIE}^{(11)}$, bem como a carência de estudos envolvendo o presente tema, o objetivo deste trabalho foi avaliar os principais tipos de produtos de origem animal que foram interceptados ou avaliados nos procedimentos de fiscalização do trânsito internacional fronteiriço entre esses três países e o Brasil, relacionar com a situação sanitária oficialmente declarada desses países fronteiriços e analisar as possibilidades de introdução de agentes infecciosos e doenças aos quais o Brasil está sujeito considerando o tipo de produtos apreendidos.

\section{Material e Métodos}

Entre os meses de janeiro e maio de 2012, foram realizadas missões a cada uma das unidades de vigilância aqui estudadas para obtenção de informações e dados de apreensões e fiscalizações, por meio da documentação emitida para cada ação de fiscalização. As visitas às unidades foram precedidas de um contato prévio e autorizações oficiais. Entre as atividades das unidades estão a fiscalização da importação e exportação de produtos agropecuários e a fiscalização do trânsito internacional de veículos e passageiros. Os formulários emitidos na interceptação e apreensão de produtos de origem animal, bem como na fiscalização do trânsito internacional de veículos e passageiros foram obtidos e, posteriormente, a análise descritiva dos dados foi realizada.

Três unidades de vigilância agropecuária foram objeto deste estudo, sendo elas localizadas na região norte do país: as Unidades de Vigilância Agropecuárias (Uvagros) de Assis Brasil, de Epitaciolândia e de Pacaraima. As características gerais dessas unidades estão na Tabela 1 e a escolha de unidades fora do âmbito do Mercosul foi devido à distinção de condição sanitária dos países não pertencentes ao Mercosul, com os quais o Brasil também faz fronteira terrestre, como Bolívia, Peru e Venezuela, sendo que este último, à época de realização do presente estudo, ainda se encontrava fora do Mercosul. Além disso, essas unidades foram escolhidas por se localizarem em regiões distantes do poder central e no Norte do país, já que as fronteiras do Mercosul são mais movimentadas e conhecidas.

Outros aspectos que envolveram a escolha das unidades aqui estudadas foram: a localização geográfica, a característica da região onde se localizam e a condição sanitária dos países fronteiriços. As unidades de Assis Brasil, Epitaciolândia e Pacaraima estão localizadas na região amazônica, onde há diversos acessos, tanto fluviais quanto terrestres. São vários rios e estradas vicinais ao longo da faixa de fronteira que permitem um livre trânsito internacional de pessoas e animais, condições que dificultam o processo de fiscalização e vigilância. Ainda, a floresta amazônica atua como barreira natural à introdução de determinados agentes de doenças animais. 
Tabela 1: Características gerais das Uvagros de Assis Brasil, Epitaciolândia e Pacaraima

\begin{tabular}{|c|c|c|c|}
\hline ESTADO & $\begin{array}{c}\text { ASSIS BRASIL } \\
\text { Acre }\end{array}$ & $\begin{array}{c}\text { EPITACIOLÂNDIA } \\
\text { Acre }\end{array}$ & $\begin{array}{c}\text { PACARAIMA } \\
\text { Roraima }\end{array}$ \\
\hline $\begin{array}{c}\text { PAÍS DE } \\
\text { ERONTEIRA }\end{array}$ & Peru & Bolívia & Venezuela \\
\hline $\begin{array}{c}\text { DADOS } \\
\text { GEOGRÁFICOS }\end{array}$ & $\begin{array}{l}\text { Área: } 4.974 \mathrm{~km}^{2} \text {; } \\
\text { População: } 6.072 \\
\text { habitantes; } \\
\text { Distância da capital } \\
\text { (Rio Branco): } 331 \mathrm{~km} \text {; } \\
\text { Acesso: Estrada do } \\
\text { Pacífico (Rodovia BR- } \\
317 \text { ); } \\
2.995 \mathrm{~km} \text { de fronteira } \\
\text { terrestre com o Peru, } \\
\text { sendo } 1.430 \mathrm{~km} \text { com o } \\
\text { Estado do Acre e } \\
1.565 \text { km com o } \\
\text { Estado do Amazonas. }\end{array}$ & $\begin{array}{l}\text { Área: } 1.655 \quad \mathrm{~km}^{2} \text {; } \\
\text { População: } 15.100 \\
\text { habitantes; } \\
\text { Distância da capital (Rio } \\
\text { Branco): } 217 \mathrm{~km} \text {; } \\
\text { Acesso: Rodovia BR- } \\
317 ; \\
3.126 \mathrm{~km} \text { de fronteira } \\
\text { terrestre com a Bolívia, } \\
\text { sendo } 386 \mathrm{~km} \text { com o } \\
\text { Estado do Mato Grosso } \\
\text { do Sul, } 780 \mathrm{~km} \text { com o } \\
\text { Estado do Mato Grosso, } \\
\text { 1.342 km com o Estado } \\
\text { de Rondônia e } 618 \mathrm{~km} \\
\text { com o Estado do Acre. }\end{array}$ & $\begin{array}{l}\text { Área: } 8.028 \mathrm{~km}^{2} \text {; } \\
\text { População: } \\
\text { 10.433 habitantes; } \\
\text { Distância da capital } \\
\text { (Boa Vista): } 198 \mathrm{~km} \text {; } \\
\text { Acesso: Rodovia } \\
\text { BR-174; } \\
1.492 \mathrm{~km} \text { de fronteira } \\
\text { terrestre com a } \\
\text { Venezuela, sendo } \\
538 \text { km com o } \\
\text { Estado do Amazonas } \\
\text { e } 954 \text { km com o } \\
\text { Estado de Roraima. }\end{array}$ \\
\hline
\end{tabular}

Fonte: IBGE(12)

\section{Resultados e Discussão}

O Brasil mantém relações comerciais com seus parceiros do Mercosul, com grande troca de mercadorias e, normalmente, há um retrospecto da qualidade sanitária destes produtos, em especial os de origem animal. Já os de fora do Bloco, como Peru, Bolívia e Venezuela, representam bem menos na balança comercial nacional de produtos de origem animal. O Siscomex é um sistema instituído pelo Decreto $\mathrm{N}^{\mathrm{o}} 660$, de 25/09/1992, onde são registrados os procedimentos de importação e exportação realizados no país. Os FFAs do MAPA têm acesso ao sistema por meio de senha, fornecida mediante cadastro e são anuentes somente na importação de produtos agropecuários de competência do MAPA, em consulta realizada em 19 jul. 2012. Dados do Siscomex $^{(13)}$ referentes ao volume líquido de importação de produtos de origem animal no ano de 2011 confirmaram isso, conforme se observa na Tabela 2.

Observou-se que 98,57\% do volume total de importação de produtos de origem animal dos seis países provêm dos integrantes do Bloco, enquanto que apenas 1,43\% vêm da Bolívia e do Peru, visto que a Venezuela aparece com zero. Entre os produtos de origem animal com maior volume de importação dos países do Mercosul estão as carnes bovinas congeladas, frescas e refrigeradas, os peixes e filés de peixes congelados e, dentre os lácteos, leite, creme de leite, requeijão e queijos ${ }^{(13)}$. Do Peru, o Brasil importou peixes congelados e moluscos com ou sem concha, em diversas formas de conservação. Da Bolívia, o Brasil importou principalmente produtos de origem animal não comestíveis, em diversas formas de conservação, utilizados na preparação de produtos 
farmacêuticos (secreções glandulares de animais utilizados como opoterápicos, como âmbarcinzento, castóreo, almíscar, bílis etc) ${ }^{(13)}$.

Tabela 2: Volume líquido em quilogramas $(\mathrm{kg})$ de importação de produtos de origem animal da Argentina, Paraguai, Uruguai (Mercosul), Bolívia, Peru e Venezuela em 2011

\begin{tabular}{|c|c|}
\hline País de origem & Volume líquido em kg \\
\hline Argentina & 168.133 .944 \\
\hline Paraguai & 8.533 .212 \\
\hline Uruguai & 98.348 .794 \\
\hline Sub-total Mercosul & 275.015 .950 \\
\hline Bolívia & 21.903 \\
\hline Peru & 4.016 .902 \\
\hline Venezuela & 0 \\
\hline Sub-total & 4.038.805 \\
\hline TOTAL & 279.054.755 \\
\hline
\end{tabular}

Fonte: Siscomex ${ }^{13}$

No período em que se esteve na Unidade de Assis Brasil, foi realizada a coleta de dados retrospectivos da movimentação na Uvagro Assis Brasil, quando foram analisados 249 formulários de Termos de Retenção de Mercadoria/Produto, emitidos no período de 2009 a 2011.

Na Uvagro Epitaciolândia, foi realizada a análise de 71 formulários utilizados na fiscalização do trânsito internacional de veículos e passageiros, sendo nove Termos de Apreensão, 19 Termos de Fiscalização de Bagagem/Encomenda e 43 Termos de Retenção de Mercadoria/Encomenda emitidos no período de 2007 a 2011. Todos traziam informações de interceptações e apreensões de produtos de origem animal. Também foi realizada análise de 484 Termos de Fiscalização do Trânsito Internacional de Passageiros, emitidos no primeiro semestre de 2009. Dados referentes ao trânsito formalizado de produtos e aos termos de apreensões nas UVAGROs de Epitaciolândia, Assis Brasil e Pacaraima são observados na Tabela 3.

A Uvagro Epitaciolândia faz fronteira com a Bolívia, sendo a cidade de Epitaciolândia contígua à cidade de Brasiléia, sendo que a primeira é fronteira com a Bolívia e a segunda é fronteira com o Peru, uma característica bastante peculiar desta Unidade, pois existem duas pontes ligando os três países. A região é considerada rota do tráfico de drogas, especialmente de pasta base de coca produzida na Bolívia e no Peru. No período estudado, houve duas apreensões de sal grosso a granel totalizando $750 \mathrm{~kg}$, que estavam sendo transportados clandestinamente, acondicionados em sacos de $40 \mathrm{~kg}$, os quais não apresentavam qualquer informação. Na ocasião da realização do presente trabalho, na Unidade de Epitaciolândia, observou-se que na região acontece semanalmente uma feira, na qual são comercializados diversos produtos agropecuários, inclusive com feirantes bolivianos vendendo produtos daquele país. 
Tabela 3: Dados obtidos referentes as UVAGROs de Epitaciolândia, Assis Brasil e Pacaraima. Brasília, 2012

\begin{tabular}{|c|c|c|c|}
\hline & ASSIS BRASIL & EPITACIOLÂNDIA & PACARAIMA \\
\hline $\begin{array}{c}\text { EXPORTAÇÃO } \\
\left(2011 \text { e } 1^{\circ} \text { semestre }\right. \\
\text { de } 2012)\end{array}$ & $\begin{array}{l}27.200 \mathrm{~kg} \text { de frango } \\
\text { congelado }\end{array}$ & $\begin{array}{l}2.137 .750 \mathrm{~kg} \text { de frango } \\
\text { congelado }\end{array}$ & $\begin{array}{l}899.434 \mathrm{~kg} \text { de carne } \\
\text { bovina congelada e } \\
541.915 \mathrm{~kg} \text { de massa } \\
\text { coalhada }\end{array}$ \\
\hline $\begin{array}{c}\text { IMPORTAÇÃO } \\
\text { (2011 e } 1^{\circ} \text { semestre } \\
\text { de } 2012)\end{array}$ & -------------------' & $\begin{array}{l}569.000 \mathrm{~kg} \text { de sal a } \\
\text { granel* }\end{array}$ & -------------------- \\
\hline APREENSÕES & $\begin{array}{l}83,0 \text { kg de laticínios; } \\
23,5 \mathrm{~kg} \text { de pescados; } \\
22,5 \mathrm{~kg} \text { de carnes; } 13,4 \\
\text { kg de apícolas; } 5,0 \mathrm{~kg} \\
\text { de uso veterinário e } \\
1,4 \mathrm{~kg} \text { de embutidos. } \\
\text { Total: } 148,8 \mathrm{~kg}\end{array}$ & $\begin{array}{l}\text { 240,6 kg de pescados; } \\
\text { 20,3 kg de laticínios; } \\
\text { 1,1 kg de embutidos e } \\
0,1 \mathrm{~kg} \text { de carnes. } \\
\text { Total: } 262,1 \mathrm{~kg}\end{array}$ & Não identificadas \\
\hline $\begin{array}{c}\text { TERMOS } \\
\text { ANALISADOS }\end{array}$ & $\begin{array}{l}249 \text { Termos de } \\
\text { Retenção de } \\
\text { Mercadoria/Produto }\end{array}$ & $\begin{array}{l}09 \text { Termos de } \\
\text { Apreensão; } 19 \text { Termos } \\
\text { de Fiscalização de } \\
\text { Bagagem/Encomenda } \\
43 \text { Termos de Retenção } \\
\text { de } \\
\text { Mercadoria/Encomenda }\end{array}$ & $\begin{array}{l}484 \text { Termos de } \\
\text { Fiscalização do } \\
\text { Trânsito } \\
\text { Internacional de } \\
\text { Passageiros }\end{array}$ \\
\hline
\end{tabular}

*A importação de sal a granel tem a anuência do MAPA porque tem como uso proposto a alimentação animal, por isso, contribui para o somatório na área animal da Unidade.

A Uvagro Pacaraima, em Roraima, faz fronteira com a Venezuela. Não foi observada demanda de importação na área animal; entretanto, na exportação de produtos de origem animal e de uso na pecuária é realizada apenas a conferência documental. Durante o presente trabalho, houve uma apreensão de uma carga clandestina de 160 pintos de um dia, oriundos da Venezuela e sem certificação sanitária, cujo veículo transportador foi interceptado devido ao alerta telefônico originado do órgão fiscalizador venezuelano. Na Uvagro Pacaraima, não foi possível identificar os principais produtos de origem animal interceptados e apreendidos; contudo, foi possível apenas quantificar o número de passageiros fiscalizados no primeiro semestre de 2009, que foram 1.921, distribuídos entre janeiro e junho de 2009, conforme a Tabela 4.

Tabela 4: Quantitativo de passageiros fiscalizados na Uvagro Pacaraima no primeiro semestre de 2009

\begin{tabular}{cc}
\hline Mês & Passageiros Fiscalizados \\
\hline Janeiro & 29 \\
Fevereiro & 524 \\
Março & 474 \\
Abril & zero \\
Maio & 146 \\
Junho & 748 \\
Total & $\mathbf{1 9 2 1}$ \\
\hline
\end{tabular}


As fronteiras constituem, em sua maioria, espaços insuficientemente integrados à economia e sociedade nacionais devido a desenvolvimentos diferentes e vulnerabilidade variável entre os países, sendo que as populações que vivem regularmente ou circunstancialmente nestes espaços têm uma intensa migração motivada pelo comércio legal ou ilegal, por trabalho estável ou eventual, por turismo e em alguns casos por situações políticas ou de conflitos ${ }^{(14)}$.

Soluções como a implantação de uma política de incentivo para manutenção de servidores em regiões inóspitas, como é o caso das Unidades de Assis Brasil, Epitaciolândia e Pacaraima se fazem necessárias. $\mathrm{O}$ estabelecimento de um rodízio ou análise prévia do perfil do candidato a exercer suas atividades nestes locais poderia ser uma alternativa de lotação e manutenção de servidores em regiões inóspitas, bem como a realização de concursos públicos regionalizados.

Os principais produtos de origem animal interceptados e apreendidos no trânsito internacional de veículos e passageiros em duas das três unidades foram laticínios, pescados, carnes, embutidos, produtos de uso veterinário e uso na alimentação animal (ração, medicamentos e insumos) e apícolas. Um importante elemento para classificar um agente microbiano como perigoso é determinar quando ou não um agente patogênico é provável de estar presente no país de origem e de qual mercadoria é derivado ${ }^{(15)}$.

Se considerarmos que os principais produtos de origem animal identificados nas interceptações realizadas pela vigilância agropecuária internacional nas fronteiras do Peru e da Bolívia são os que provavelmente mais ingressam clandestinamente no Brasil, podemos relacioná-los com a situação sanitária do respectivo país de origem. Com base nesta premissa, foi possível estabelecer uma relação dos principais produtos de origem animal identificados com ingresso clandestino no Brasil pela Uvagro Assis Brasil com a condição sanitária do Peru. Considerando que laticínios, pescados e produtos apícolas estão entre os com maior volume de apreensões, vemos o risco de introdução dos agentes causadores da brucelose (B. melitensis) e da paratuberculose, através dos laticínios, e a podridão americana e podridão europeia da abelha melífera através dos produtos apícolas. O Peru ou não disponibilizou informações sobre sua condição sanitária, ou teve registros mais recentes destas doenças, enquanto que no Brasil algumas nunca ocorreram ${ }^{(11)}$, revelando que o país possui uma condição sanitária superior ao Peru em relação às doenças animais citadas.

Se forem considerados os principais produtos de origem animal identificados como os de maior volume de apreensões na Uvagro Epitaciolândia, fronteira com a Bolívia, tem-se uma situação distinta. Pescados, laticínios e embutidos foram apreendidos por não estarem acompanhados de certificação sanitária, o que os tornam sem procedência e sem garantias de sanidade. Com isso, observam-se possibilidades de introdução da brucelose e da paratuberculose, através dos laticínios, e da síndrome reprodutiva e respiratória dos suínos, através dos embutidos. A Bolívia figurou como suspeita para as duas primeiras enfermidades ${ }^{(11)} \mathrm{e}$, embora sem doença clínica, apresentou infecção demonstrada para a terceira. O Brasil teve, em 2003, o último registro de paratuberculose e é livre tanto da brucelose causada por Brucella melitensis como da síndrome reprodutiva e respiratória dos suínos, condição que o coloca em melhor situação sanitária que a Bolívia, em relação a essas doenças. A identificação do perigo é um passo essencial que deve ser dado em direção à análise de risco, que envolve a detecção dos agentes patogênicos que podem estar associados a uma mercadoria importada e que poderiam potencialmente produzir consequências adversas ${ }^{(15)}$.

Embora em menor volume de apreensões, as carnes apareceram como produtos de origem de animal interceptados nas Unidades de Assis Brasil e Epitaciolândia. Considerando que provavelmente também ingressaram clandestinamente, não seria prudente descartar o risco de 
introdução da febre aftosa, por exemplo. Apesar de a febre aftosa ter sido relatada nos quatro países - Brasil, Bolívia, Peru e Venezuela - teve na Venezuela o registro mais recente, em 2010.

A situação sanitária de um país é potencialmente dependente daquela de outros países. Basta um país negligenciar suas obrigações de vigilância para ameaçar todo o planeta ${ }^{(16,17)}$. A febre aftosa possui enormes implicações sobre o comércio global e é uma das doenças pecuárias mais altamente reguladas no mundo, mobilizando grandes esforços internacionais no controle da disseminação do vírus através da restrição do movimento de animais e produtos de origem animal ${ }^{(10)}$.

Como o comércio internacional ocorre desde o início da civilização humana, este pode acontecer tanto pela via formal quanto pela informal. A via formal ocorre por meio de acordos bilaterais entre os países de origem e de destino das mercadorias, os quais definem as condições em que essas transações terão lugar, incluindo restrições tarifárias e não tarifárias, bem como exigências sanitárias a serem cumpridas. Esses requisitos sanitários e restrições comerciais são implementados por meio das agências governamentais regulatórias, que fornecem a fundamentação legal sobre o comércio formal, visando mitigar os riscos de introdução e disseminação de doenças através do comércio. O termo "comércio informal" refere-se a atividades ilegais, extralegais e mercados paralelos. O contrabando é um clássico exemplo de comércio ilegal, quando um produto é proibido num país, mas ingressa apesar disso. Já os mercados paralelos referem-se aos mercados que estão normalmente fora da jurisdição regulatória, como os de colecionadores de animais que trocam exemplares. E as atividades extralegais são aquelas tecnicamente ilegais para as quais se faz "vista grossa". Um exemplo disso são os itens alimentícios trazidos nas bagagens de passageiros internacionais, como queijos artesanais, cujo ingresso é regulado no país, mas nem sempre as autoridades aduaneiras os interceptam. Vemos que os riscos devido ao comércio informal são reconhecidos, mas raramente avaliados ${ }^{(18)}$.

A introdução do vírus da febre aftosa é sempre devido a ações ilegais. Os focos de febre aftosa ocorridos na Europa entre 1991 e 1996 tiveram como origens o contrabando de animais vivos procedentes de países vizinhos infectados, a importação de gado com certificado sanitário falsificado, a importação ilegal de ovelhas e a importação de carne, entre outros.

Mais recentemente, em 2001, o contrabando de produtos cárneos foi suspeito de ter sido a fonte do foco de febre aftosa ocorrido no Reino Unido ${ }^{(18,19)}$. O papel dos pequenos ruminantes com infecção clinicamente inaparente foi dramaticamente ilustrado no foco de febre aftosa ocorrido no Reino Unido em 2001. Enquanto a infecção provavelmente não se iniciou com a importação de ovelhas infectadas ela se estabeleceu em ovelhas e, devido ao fato de as ovelhas não apresentarem sinais clínicos óbvios da doença, os animais da fazenda índice foram vendidos e espalharam a infecção pelo país antes que o diagnóstico fosse realizado. A ampla disseminação da infecção durante esse período fez com que os esforços de controle fossem extremamente difíceis, prolongados e dispendiosos ${ }^{(10)}$. A boa prevenção, acompanhada de medidas apropriadas, provaram ser muito menos onerosas do que o controle de focos de doenças ${ }^{(17)}$.

Há que considerar outra ameaça além das já discutidas, que é o bioterrorismo. A disseminação internacional de doenças infecciosas animais pode ocorrer de forma natural, acidental ou intencional, resultado do movimento de animais, produtos de origem animal ou culturas de organismos infecciosos. O bioterrorismo é o terrorismo pela liberação intencional ou disseminação de agentes biológicos (bactérias, vírus ou toxinas) que podem ocorrer em sua forma natural ou modificada. A vulnerabilidade dos alimentos e do setor agrícola à introdução de agentes biológicos é variável, mas é consenso que as indústrias pecuárias são relativamente vulneráveis a ataques 
intencionais ${ }^{(20)}$.

O impacto sobre os países exportadores, incluindo os países desenvolvidos, tem sido sentido, mesmo na ausência de reconhecimento de introdução intencional de doenças animais ou veiculadas por alimentos, devido ao aumento do rigor nos padrões de importação e as regulamentações as quais têm sido impostas para a proteção contra tais introduções. Esses novos requisitos para inspeção e demonstração de isenção de doença têm, em alguns países em desenvolvimento, gerado dificuldade de encontrar fontes disponíveis ${ }^{(20)}$. Se o Brasil garantir a inocuidade de seus produtos pecuários, através de um sistema de produção seguro e um serviço de vigilância agropecuária eficiente, pode consolidar-se como uma destas fontes.

Uma das mais importantes manifestações de globalização econômica é a expansão do comércio internacional. É amplamente sabido que medidas técnicas, bem como a qualidade dos alimentos e requisitos sanitários e fitossanitários podem impedir o comércio, particularmente no caso dos países em desenvolvimento. Assim como a liberação de tarifas e de restrições quantitativas no comércio de produtos agropecuários progrediu, aumentaram também as medidas técnicas a serem atendidas, como regulamentação da segurança alimentar, exigências na rotulagem e padrões de qualidade e composição dos alimentos. Essas medidas podem atuar, implícita ou explicitamente, como barreiras ao comércio, da mesma forma que as tarifas e as restrições quantitativas ${ }^{(21)}$.

Uma boa política de governança veterinária deve ser alicerçada em uma legislação sanitária apropriada e suficientes recursos humanos, administrativos, gerenciais, técnicos e financeiros. Os elementos-chave para isso são direcionar para as ocorrências nacionais, regionais e globais de doenças humanas e animais capacidade de vigilância, diagnóstico (estrutura laboratorial), informação e programas de erradicação e controle em concordância com os padrões da OIE. Portanto, vigilância, diagnóstico precoce e uma rápida resposta profissional, baseada em informações transparentes e tempestivas, são essenciais ${ }^{(16)}$.

Vale considerar o fato de que o processo de privatização dos serviços oficiais de saúde pública animal e humana teve efeito negativo em termos de recursos humanos e infraestrutura. Algumas funções essenciais, como vigilância epidemiológica e normatização, enfraqueceram, chegando a desaparecer em alguns países. Muitos pequenos pecuaristas, os quais constituem a maioria dos produtores, não possuem poder aquisitivo para acessar os serviços privados, ficando à margem deles sem a intervenção do Estado. Como exemplo, num país da região andina, nas Américas, a abrupta privatização dos serviços de saúde animal sem prover uma eficiente transição levou ao desaparecimento do sistema de vigilância epidemiológica. Como resultado, a febre aftosa foi introduzida por um país vizinho infectado, pois, com a ausência de um sistema de vigilância, a doença se espalhou por todo o território em apenas três semanas, após quase 15 anos sem registro de casos da enfermidade ${ }^{(22)}$.

Tanto os serviços veterinários públicos como os privados devem ter a capacidade de prevenir, detectar e controlar doenças animais em consonância com os padrões internacionais do Código de Saúde dos Animais Terrestres da $\mathrm{OIE}^{(16)}$. O desafio de muitos países desenvolvidos atualmente é desenvolver modelos alternativos com uma ótima integração entre a iniciativa privada e o setor público, para assegurar uma efetiva prestação dos serviços sociais ${ }^{(22)}$.

Atualmente, os países baseiam suas decisões de importações em medidas sanitárias conforme os padrões da OIE, sem requerer nenhuma justificativa adicional. Entretanto, os países podem introduzir medidas sanitárias que resultem em um nível de proteção mais alto do que aquele alcançado e aplicado pelos padrões internacionais, desde que apresentem justificativa técnica 
através de uma avaliação de risco com base científica ${ }^{(23)}$.

\section{Conclusões}

Os principais tipos de produtos de origem animal clandestinos que foram interceptados e apreendidos nos procedimentos de fiscalização do trânsito internacional fronteiriço terrestre no Brasil em 2011 e em parte do ano de 2012 procedentes do Peru e da Bolívia nas Uvagros estudadas foram os laticínios, pescados, carnes e embutidos, produtos apícolas e produtos de uso veterinário. Da Venezuela (Uvagro Pacaraima), observou-se o trânsito rodoviário clandestino de aves comerciais. Devem ser melhores avaliadas as possibilidades de introdução de agentes infecciosos e doenças as quais o Brasil está sujeito considerando o tipo de produtos apreendidos, considerando o estado sanitário dos países aqui estudados, em face da natureza clandestina do transito dos animais e seus produtos por estas fronteiras terrestres.

\section{Agradecimentos}

À Secretaria de Defesa Agropecuária do Ministério da Agricultura, Pecuária e Abastecimento (SDA/MAPA), a Coordenação Geral do VIGIAGRO (VIGIAGRO/MAPA), as Superintendências Federais da Agricultura do Acre e de Roraima (MAPA/SFA/AC e MAPA/SFA/RR). Ao CNPq pelas bolsas de produtividade em pesquisa (PQ) concedidas aos dois últimos autores (CMM e CBM).

\section{Referências}

1. Salman MD, Stark KDC., Zepeda C. Quality assurance applied to animal disease surveillance systems. Rev Sci Tech Off Int Epiz. 2003 Aug;22(2):689-96.

2. Carvalho LFR, de Melo CB, McManus C, Haddad JPA. Use of satellite images for geographical localization of livestock holdings in Brazil. Prev Vet Med. 2012;103(1):74-77.

3. de Melo CB, de Sa MEP, Alves FF, McManus C, Aragao LF, Belo BB, Campani PR, da Matta Ribeiro AC, Seabra CI, Seixas L. Profile of international air passengers intercepted with illegal animal products in baggage at Guarulhos and Galeão airports in Brazil. SpringerPlus. 2014;3:69.

4. Moura JA, McManus C, Bernal FEM, de Melo CB. An analysis of the 1978 African swine fever outbreak in Brazil and its eradication. Rev Sci Tech Off Int Epiz. 2010 Dec;29(3):549-63.

5. de Melo CB, de Sa MEP, Souza AR, de Oliveira AM, Mota PMPC, Campani PR, Luna JO, Pinto SC, Schwingel FF, McManus C, Seixas L. Bacteria in Dairy Products in Baggage of Incoming Travelers, Brazil. Emerg Infect Dis. 2014; 20(11):1933-35.

6. de Melo CB, de Sa, MEP, Sabino VM, Boechat-Fernandes MF, Santiago MT, Schwingel FF, Freitas C, Magioli CA, Cabral-Pinto S, McManus C, Seixas L. Microbiological detection of bacteria in animal products seized in baggage of international air passengers to Brazil. Prev Vet Med. 2015 Jan;118(1):22-7.

7. Cobb SP. The spread of pathogens through trade in poultry hatching eggs: overview and recent developments. Rev Sci Tech Off Int Epiz. 2011;30(1):165-75. 
8. Beato MS, Capua I. Transboundary spread of highly pathogenic avian influenza through poultry commodities and wild birds: a review. Rev Sci Tech Off Int Epiz. 2011;30(1):51-61.

9. Pharo H, Cobb SP. The spread of pathogens through trade in pig meat: overview and recent developments. Rev Sci Tech Off Int Epiz. 2011;30(1):139-48

10. Sherman DM. The spread of pathogens through trade in small ruminants and their products. Rev Sci Tech Off Int Epiz. 2011;30(1),207-17.

11. OIE. World Organisation for Animal Health. 2012 [citado 2012 Jul 18]; Disponível em: <http://www.oie.int >. Acesso em março de 2015.

12. Instituto Brasileiro de Geografia e Estatística (IBGE). 2012. [citado 2012 Jul 23]; Disponível em: <http://www.ibge.gov.br >. Acesso em março de 2015.

13. Siscomex. Sistema Integrado de Comércio Exterior. Ministério do Desenvolvimento, Indústria e Comércio (MDIC). 2012. [citado 2012 Jul 19]; Disponível em: <http://www.mdic.gov.br/siscomex/siscomex.html $>$. Acesso em março de 2015.

14. Quirós HM, González HR, Vergara JFV. Armonización de la vigilância sanitaria interfronteriza: una propuesta vinculante en salud internacional. Rev Panam Salud Public. 2011;30(2):148-52.

15. Sugiura K, Murray N. Risk analysis and its link with standards of the World Organisation for Animal Health. Rev Sci Tech Off Int Epiz. 2011;30(1):281-88.

16. Schneider H. Good governance of national Veterinary Services. Rev Sci Tech Off Int Epiz. 2011;30(1):325-38.

17. Pastoret PP, Chaisemartin D. The importance of governance and reliable veterinary certification. Rev Sci Tech Off Int Epiz. 2011;30(1):347-52.

18. Hueston W, Travis D, van Klink E. Optimising import risk mitigation: anticipating the unintended consequences and competing risks of informal trade. Rev Sci Tech Off Int Epiz. 2011;30(1):309-16.

19. Leforban Y. Prevention measures against foot-and-mouth disease in Europe in recent years. Vaccine. 1999 Mar 26;17(13-14):1755-9.

20. Clarke NP, Rinderknecht JL. Bioterrorism: intentional introduction of animal disesase. Rev Sci Tech Off Int Epiz. 2011;30(1):131-38.

21. Henson S, Loader R. Barriers to agricultural exports from developing countries: the role of sanitary and phytosanitary requirements. World Develop. 2001;1(29):85-102.

22. Arambulo III, P. International programs and veterinary public health in the Americas - Success, challenges and possibilities. Prev Vet Med. 2008 Sep 15;86(3-4):208-15.

23. Thiermann, A. Globalization, international trade and animal health: the new roles of OIE. Prev Vet Med. 2005; 67(2-3):101-108. 